\title{
A Case: Paraquat (Pesticide) and Skin Involvement
}

\author{
Bahadir Yazicioglu* \\ Department of Family Medicine, Faculty of Medicine, Ondokuz Mayis University, Samsun, Turkey
}

Email address:

bahadiryazicioglu@gmail.com (B. Yazicioglu)

\section{To cite this article:}

Bahadir Yazicioglu. A Case: Paraquat (Pesticide) and Skin Involvement. Journal of Family Medicine and Health Care. Vol. 1, No. 2, 2015, pp. 24-26. doi: 10.11648/j.jfmhc.20150102.12

\begin{abstract}
Paraquat is a pesticide which was started to be used in agriculture and gardening around the world since the middle of 1960's. Pesticides taken for suicide or by accident can have serious side effects on the body. Paraquat taken in the body mostly orally and transdermal, inhalation and although rarely intravenous way. Erythema, itching, swelling and bullae with exudative discharge in almost all of the left foot and leg was observed in a 56 year old man for fifteen days. On the day his complaints started, he used agricultural pesticide (paraquat) while it was raining. The patient was in a good general condition when he arrived. The patient was put on bed rest. Left leg elevation and ice compress for 15 minutes at least two times a day was given in order to decrease edema. In order to prevent infection and for sterilization, leg cleaning with tincture of iodine solution was recommended. Topical and systemic anti-biotherapy was started. Hemorrhagic lesions started to scab on the third days after resting and treatment were started. Edema became lower. The cure was completed in two weeks.
\end{abstract}

Keywords: Paraquat, Pesticide, Skin Involvement

\section{Introduction}

Pesticides are chemical materials used in order to destroy or decrease the harmful effects of creatures such as insects, weeds, fungi and rodents which survive in and around the human habitat and decrease the nutritional value of agricultural nutritional sources or harm them[1]. Paraquat is a pesticide which was started to be used in agriculture and gardening around the world since the middle of 1960's and considered industrially safe[2][3]. Pesticides taken for suicide or by accident can have serious side effects on the body[4]. Paraquat taken in the body mostly orally and transdermal, inhalation and although rarely intravenous way is a dipyhdinium compound which may cause poisoning (1,1'-dimethyl-4,4'- bipyridinium dichloride) [5][6]. It may have toxic effects which may lead to multi organ deficiency in high doses[7]. It is considered that Paraquat exposure is also related to Parkinson disease[8]. Concentrate formulated paraquat has a strong irritant effect on epithelial tissue especially. It causes erythema, swelling and ulceration on the skin [9]. Paraquat's effects on the body occur over the free radicals formed by oxidation/reduction cycle in tissues. These free radicals become superoxide radicals in the presence of oxygen and cause cell damage[4][5][10]. Our aim in this case presentation was to share a paraquat exposure and literature scanning.

\section{Case}

Erythema, itching, swelling and bullae with exudative discharge in almost all of the left foot and leg was observed in a 56 year old man for fifteen days. On the day his complaints started, he used agricultural pesticide while it was raining. The patient mentioned that the pesticide came in contact with especially his left leg due to the rain and that evening his complaints started with insignificant itching and a mild erythema. The erythema in his left ankle started to spread upwards toward his knee in 2-3 days. 2-3 red lesions appeared on his ankle where there was erythema before. His itching became very intensive. At the end of 5-6 days the number and the lesions in his ankle became larger and more in number and they were also seen in upper parts of the ankle up to the knee. Edema started to form slowly under his left knee after a week. The lesions which appeared initially started to scab and new lesions were also present in the area. At the end of ten days, edema increased and some of the lesions were still present with scabs and also some new lesions formed.

The patient was in a good general condition when he arrived, blood pressure: 130/80mmHg, pulse:92/minutes, hemoglobin: 13,6 g/dl, number of leukocytes: $8340 / \mu \mathrm{l}$, urea: $24 \mathrm{mg} / \mathrm{dl}$, creatinine: 1,2 mg/dl, AST: $26 \mathrm{U} / 1$, ALT: $18 \mathrm{U} / 1$, sodium: 134 mmol/1, potassium: $3,9 \mathrm{mmol} / 1$, chlorine: $105 \mathrm{mmol} / \mathrm{l}$, calcium: was determined as $8,2 \mathrm{mmol} / \mathrm{l}$. Significant amount of edema, 
hemorrhagic erythema and burst bullae were present under the left knee.

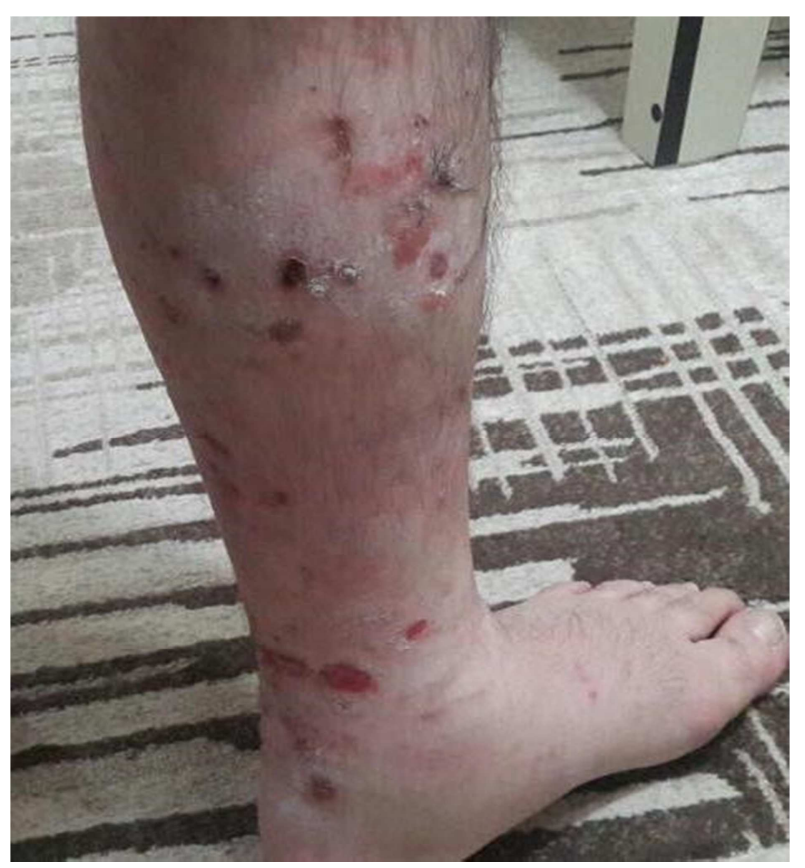

Figure 1. Skin Lesions.

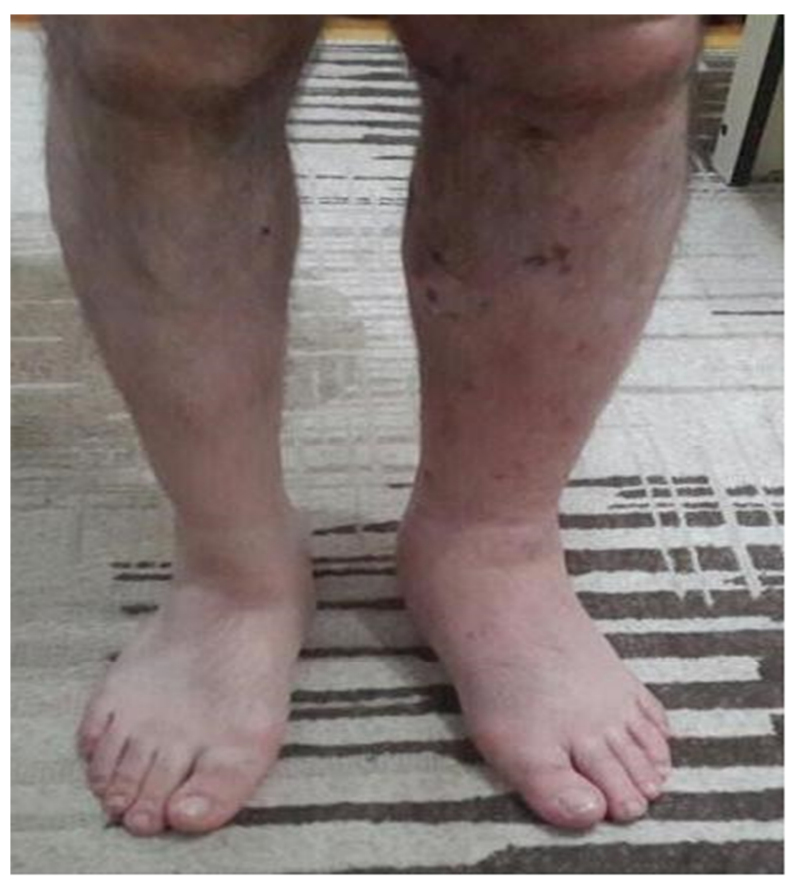

Figure 2. Edema and size difference between legs.

The patient was put on bed rest. Left leg elevation and ice compress for 15 minutes at least two times a day was given in order to decrease edema. Consultation was made with dermatology department and steroid treatment was given in order to decrease inflammatory effect. In order to prevent infection and for sterilization, leg cleaning with tincture of iodine solution was recommended. Topical and systemic anti-biotherapy was started. Hemorrhagic lesions started to scab on the third days after resting and treatment were started.
Edema became lower. The cure was completed in two weeks.

\section{Discussion}

Pesticides are used commonly in the whole world. Serious side effects may be observed due to common use. Paraquat is a pesticide which may have a toxic effect by entering the human body in several ways. Concentrated paraquat may have an abrasive effect in contact with skin. Multi-organ deficiencies mainly in lung, liver and kidney may occur in serious paraquat poisoning[7]. The time spent before starting the treatment and applied dose directly effects the clinical course of the disease.[11]. Possibility and rate of death increases as the paraquat concentration increases in the body[4]. So it is stated that washing the affected area, nails and hair with plenty of soapy water in case of contact is effective in treatment[12]. In literature it is observed that paraquat is also used as a poison [5]. Determining the way of exposure in patient anamnesis may give us an idea on whether the exposure was accidental or intentional.

Considering the anamnesis, condition, location and severity of the lesions of the patient in this case, paraquat penetrated in the body through skin.

The main aim of the treatment is decreasing the absorption of paraquat through the skin and making a symptomatic treatment [5].

In this case, commonly used pesticides entered the body through skin and caused an infection. Starting with a simple itching and erythema, an inflammatory process started after a rapid progress.

Especially learning the exposure way by anamnesis and providing an anti-inflammatory and symptom-based treatment would be appropriate for these patients.

\section{References}

[1] N. Sataloğlu, B. Aydın, and A. Turla, "Pestisit Zehirlenmeleri," TSK Koruyucu Hekim. Bülteni, vol. 6, no. 3, pp. 169-174, 2007.

[2] J. Keir Howard, "Paraquat: A review of worker exposure in normal usage," Occup. Med. (Chic. Ill)., vol. 30, no. 1, pp. 6-11, 1980.

[3] C. Wesseling, B. Van Wendel De Joode, C. Ruepert, C. León, P. Monge, H. Hermosillo, and T. J. Partanen, "Paraquat in developing countries," Int. J. Occup. Environ. Health, vol. 7, no. 4, pp. 275-286, 2001.

[4] A. M. Sabzghabaee, N. Eizadi-Mood, K. Montazeri, a. Yaraghi, and M. Golabi, "Fatality in paraquat poisoning," Singapore Med. J., vol. 51, no. 6, pp. 496-500, 2010.

[5] S. Eraybar, A. Kose, F. Ozdemir, and S. Aydin, "Paraquat Intoxication: Case report," Gaziantep Med. J., vol. 17, no. 3, p. $1,2011$.

[6] T. Spangenberg, H. Grahn, H. van der Schalk, and K. Kuck, "Paraquat poisoning. Case report and overview," Medizinische Klin. - Intensivmed. und Notfallmedizin, vol. 107, no. 4, pp. 270-274, 2012. 
[7] C. Sittipunt, "Paraquat Poisoning," Respir. Care, vol. 50, no. 3, pp. 383-385, 2005.

[8] T. Baltazar, R. J. Dinis-Oliveira, J. A. Duarte, M. de Lourdes Bastos, and F. Carvalho, "Paraquat research: do recent advances in limiting its toxicity make its use safer?," $B r . J$. Pharmacol., vol. 168, no. 1, pp. 44-45, 2013.

[9] J. a Vale, T. J. Meredith, and B. M. Buckley, "Paraquat poisoning: clinical features and immediate general management.," Hum. Toxicol., vol. 6, no. 1, pp. 41-47, 1987.

[10] K. Raghu, V. Mahesh, P. Sasidhar, P. R. Reddy, V.
Venkataramaniah, and A. Agrawal, "Paraquat poisoning: A case report and review of literature," J. Fam. Community Med., vol. 20, no. 3, pp. 198-200, 2013.

[11] V. C. Nayak, S. M. Bakkannavar, S. Sharma, and M. Sharma, "Paraquat Poisoning - A Case Report," Indian J. Forensic Community Med., vol. 2, no. 1, pp. 67-70, 2015.

[12] Q. Zhou, B. Kan, X. Jian, W. Zhang, H. Liu, and Z. Zhang, "Paraquat poisoning by skin absorption: Two case reports and a literature review," Exp. Ther. Med., vol. 6, no. 6, pp. 1504-1506, 2013. 